
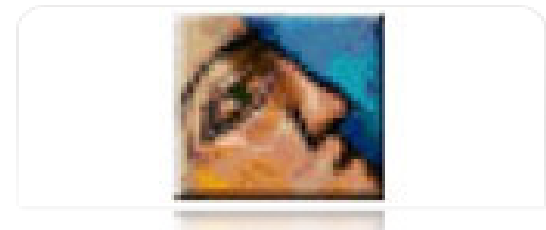

\author{
Diálogos Revista Electrónica de Historia \\ E-ISSN: 1409-469X \\ historia@fcs.ucr.ac.cr \\ Universidad de Costa Rica \\ Costa Rica
}

Cabezas Bolaños, Esteban

El papel de la archivística en la nueva sociedad de la información

Diálogos Revista Electrónica de Historia, vol. 1, núm. 2, enero-marzo, 2000, p. 0

Universidad de Costa Rica

San Pedro de Montes de Oca, Costa Rica

Disponible en: http://www.redalyc.org/articulo.oa?id=43910206

- Cómo citar el artículo

- Número completo

- Más información del artículo

Página de la revista en redalyc.org

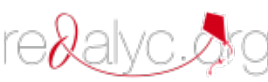

Sistema de Información Científica

Red de Revistas Científicas de América Latina, el Caribe, España y Portugal

Proyecto académico sin fines de lucro, desarrollado bajo la iniciativa de acceso abierto 


\section{El papel de la archivística en la nueva sociedad de la información}

\section{Esteban Cabezas Bolaños}

En los últimos años y ante el avance progresivo de una nueva sociedad de la información se ha experimentado una serie de cambios y transformaciones producto de las nuevas tecnologías, que han promovido en millones de personas, hogares y oficinas, una comunicación electrónica mediante estándares universales y abiertos.

Esta nueva tendencia ha generado que en aquellas empresas e instituciones generadoras de información como son archivos, bibliotecas y centros de documentación cambien sus estrategias y se adapten a las nuevas tecnologías.

La archivística moderna se concibe como una ciencia que estudia la naturaleza de los archivos, su organización, los principios para su conservación y los medios para prestar un servicio. Tradicionalmente se ha considerado que el manejo de información en instituciones públicas y privadas se centran en aquellas etapas archivísticas de gestión y archivo central para la documentación de carácter administrativo y una vez que a adquirido valor científico cultural, se envía a su destino final en los archivos históricos, siempre basado en su procedencia y organicidad institucional.

Este modelo a empezado a manifestar señales de agotamiento y desgaste ante las nuevas tendencias mundiales en el ámbito económico y político, y al rápido avance de la tecnología que ha generado un cambio en los soportes tradicionales el cual ha demandado un nuevo tratamiento archivístico ante las exigencias de una nueva sociedad dependiente de información.

La sociedad de la información está unida a dos fenómenos que son: cultura y educación, las cuales deben darle un amplio apoyo que le permita su inserción en las diferentes actividades de una sociedad. El que una colectividad se inserte en la sociedad de la información dependerá de estos dos factores y nunca por medio de imposiciones políticas o demagógicas.

Al hablar de esta nueva sociedad aceptamos que el motor es la información, sin descuidar otras actividades como las agrícolas e industriales que han generado y requerido información.

Lo anterior es un proceso que suma dos niveles educativos y culturales que se separan en dos ideas; 
1. Información: es el primer peldaño para llegar al conocimiento, se registra en un medio que puede ser físico o electrónico.

2. Conocimiento: lo que adquiere, posesiona y procesa la información que se aplica o permite generar nuevo conocimiento.

Ambas ideas requieren de funciones mentales específicas de reflexión y observación. La información debe saberse usar porque el estudio, la crítica y el análisis de estos datos crearán un nuevo conocimiento que puede generar poder.

La información custodiada en los archivos tiene un valor y se debe hacer un esfuerzo para que el usuario la valore y de una retribución por ella. De esta manera, para obtener acceso a la sociedad de la información el Estado debe hacer un gran esfuerzo para que todo el conocimiento se distribuya en forma equitativa a todos los niveles de la sociedad.

Lo anterior nos lleva a tomar en cuenta el proceso de globalización el cual rompe con los conceptos de centralización administrativa, fronteras, divisiones políticas y culturales imponiéndonos una sola cultura mundial. Este concepto junto a la creación de grandes áreas comerciales ha generado que el manejo de información en el ámbito interno de una empresa o institución y su relación con otras deba ser ágil, eficiente y competitivo.

En este campo las nuevas tecnologías han contribuido a acelerar aun más estas tendencias a través de mecanismos como la Internet que nos permite comunicarnos a nivel mundial, la extranet que es la interacción entre diferentes empresas y la intranet que es la comunicación entre los individuos de una misma compañía.

Lo anterior nos debe llevar a replantear la posición del archivista y el tratamiento archivístico dado en la documentación tanto en instituciones públicas como en la empresa privada. Los nuevos cambios demandan al archivista poder ofrecer información no sólo a la administración interna sino también a otras instituciones o empresas que a través de medios electrónicos solicitan información de una manera ágil e inmediata.

La información no sólo define y agiliza las relaciones entre los diversos sectores en una cadena de investigación, sino que en muchos negocios constituye la base de la ventaja competitiva, incluso cuando la información es completamente trivial y el producto o servicio es físico. Lo anterior genera que un manejo de información eficiente marque la diferencia entre la ventaja productiva sobre la competencia o la pérdida de mercados.

Es importante dejar claro que la archivística debe abandonar sus áreas de trabajo tradicional, relegadas en aquellas oficinas públicas productora del patrimonio documental nacional. Ante los cambios que se perfilan para los próximos años se debe ampliar las expectativas de acción a las empresas y 
corporaciones privadas y generar un manejo de información que facilite su trámite administrativo, la toma de decisiones y las estrategias de mercado.

Las compañías, instituciones o sociedades son empresas de información que en función de sus actividades no solamente generan documentación que atestigua sus actividades e historia institucional, sino que recibe $y$ produce una cantidad de información que le permite desembolverse en un mundo cada vez más agresivo y competitivo. Ante esto la archivística tiene una gran ventaja sobre las otras ciencias de la información y es su carácter de exclusividad.

Cuando un usuario busca información en una biblioteca o en un centro de documentación, sabe que si el servicio no es eficiente o de su agrado podrá conseguir dicho material en otro centro de información cercano o por la Internet. Por el contrario, al solicitar documentación en un archivo sabe que es única y que solo allí la podrá encontrar, de manera que si el servicio no es ágil o eficiente le quedará dos caminos, abandonar su proyecto o resignarse y armarse de paciencia.

Esta situación es promovida por muchos archivistas quienes elaboran instrumentos descriptivos deficientes alegando que la responsabilidad de búsqueda e investigación está en el usuario, generando a largo plazo la creación de archivos que no estarán adaptados a los nuevos cambios y requisitos que la futura sociedad mundial exige.

Para poder enfrentar estos cambios la archivística debe tomar en cuenta las demandas de información del cliente, de manera que el archivista interactúe con personas, lugares, circunstancias y actividades, que generen un sentimiento de lealtad y dependencia por parte del usuario hacia el archivo. Para ello es importante crear una estrategia de divulgación que le permita al usuario manipular un proceso de búsqueda menos complicado, más conveniente, menos costoso y más amigable.

Las anteriores son estrategias por las cuales los archivistas se verán en la obligación de interactuar con otras áreas de las ciencias de la información, de manera que la mejor forma de mantener la atención del usuario es creando una estrategia que se basen en la diferenciación: ofrecer algo que el usuario valore y la competencia no tenga.

De esta manera la archivística podrá ser una pieza fundamental en la sociedad de la información no sólo generando documentación que atestigua las actividades e historia de una sociedad, sino un organismo vivo que recibe y produce una cantidad de información que le permita desenvolverse en un mundo cada vez más competitivo y cambiante.

También nos permite perpetuar el conocimiento que la sociedad ha generado con el fin de alcanzar un mayor bienestar social. Pero, para que 
todo ello se cumpla la sociedad de la información requiere altos niveles de alfabetización, hábitos de lectura y ámbitos de uso intensivo de información. 